\title{
Phage therapy as an alternative or complementary strategy to prevent and control biofilm-related infections

\author{
DP Pires ${ }^{1}$, LDR Melo ${ }^{1}$, D Vilas Boas, S Sillankorva and
} \\ J Azeredo
}

\begin{abstract}
The complex heterogeneous structure of biofilms confers to bacteria an important survival strategy. Biofilms are frequently involved in many chronic infections in consequence of their low susceptibility to antibiotics as well as resistance to host defences. The increasing need of novel and effective treatments to target these complex structures has led to a growing interest on bacteriophages (phages) as a strategy for biofilm control and prevention. Phages can be used alone, as a cocktail to broaden the spectra of activity, or in combination with other antimicrobials to improve their efficacy. Here, we summarize the studies involving the use of phages for the treatment or prevention of bacterial biofilms, highlighting the biofilm features that can be tackled with phages or combined therapy approaches.
\end{abstract}

\begin{abstract}
Address
CEB - Centre of Biological Engineering, LIBRO - Laboratório de Investigação em Biofilmes Rosário Oliveira, University of Minho, 4710-057 Braga, Portugal

Corresponding author: Azeredo, J (jazeredo@deb.uminho.pt)

${ }^{1}$ These authors contributed equally to this review.
\end{abstract}

Current Opinion in Microbiology 2017, 39:48-56

This review comes from a themed issue on Antimicrobials

Edited by Olga Genilloud and Rolf Mueller

http://dx.doi.org/10.1016/j.mib.2017.09.004

1369-5274/@ 2017 Published by Elsevier Ltd.

\section{Introduction}

Biofilms are microbial communities adhered to surfaces, or formed on air-liquid interfaces, and are composed by cells embedded in a self-produced polymeric matrix of polysaccharides, proteins, nucleic acids and lipids [1]. These microbial structures are involved in many difficult to treat chronic infections on account of their tolerance to antibiotics and host immune defences. Accordingly, due to the failures of antibiotic therapy toward bacterial biofilms and also the emergence of multidrug-resistant bacterial strains, which currently constitutes one of the most widespread public health concerns, there is today a renewed interest in alternative therapeutic modalities to treat biofilm-associated infections, such as phage therapy. Bacteriophages (phages) are natural predators of bacteria and have been considered as a promising strategy against bacterial biofilms. Several studies have shown that phages can effectively infect and lyse cells present in single and polymicrobial species biofilms [2,3], which supports the concept of phage therapy as an alternative or complementary strategy to prevent and control biofilm-related infections. The interaction between phages and biofilms is a rather complex process [4]. Theoretically, the close proximity of cells within the biofilm structure could enhance phage-host interaction and facilitate phage infection $[5,6]$. Conversely, the biofilm structure and composition as well as the physiological state of the biofilm cells may be an obstacle to phage infection [4]. It must be stressed that phage/biofilm interactions are highly dependent on the bacterial host strain, the phage characteristics, and the biofilm structure and its composition. The biofilm formation set-up has a great impact on the biofilm characteristics making it difficult if not impossible to withdraw clear conclusions based on the state of art, regarding how phages interact with biofilms and what phage characteristics are in need to make them good biofilm controllers. Moreover, most of the studies do not mimic real clinical biofilms, usually formed by polymicrobial populations and human cells. Besides, measurements of phage's effectiveness against biofilms is based on the overall outcome of phage infection. There is a limited knowledge of how phages interact with the different population of bacterial cells that compose the biofilm. So, this review is restricted to the current knowledge of how phages interact with biofilms alone or combined with other antibiofilm approaches highlighting the limitations as well as the strategies that can be used to overcome biofilm barriers and enhance phage therapy.

\section{Limitations of bacteriophages when used as anti-biofilm agents}

It is well known that phages are currently considered as promising antimicrobial agents for biofilm prevention and control $[7,8]$. Nonetheless, although several studies have reported significant reductions in mono and dual-species biofilms after phage treatment [2,3,9-12], the complete eradication of biofilms is an almost impossible task [13 $\left.{ }^{\circ}\right]$. Phages need to reach their host bacteria and attach to specific receptors located at cell surfaces before infection 
and replication inside their hosts is initiated. The access to host receptors in planktonic cultures is easier, since the receptors are fully available for phage docking and not surrounded by a matrix as found in biofilm cells. The biofilm matrix, the reduced metabolic activity of biofilm cells and the proliferation of phage-resistant phenotypes within the biofilm are some of the major challenges to the application of phage therapy for biofilm control.

\section{Diffusional limitation through the biofilm matrix}

It is estimated that only $10 \%$ of biofilm dry biomass are cells. The biofilm matrix comprises the other $90 \%$ and it is composed by different types of polymers, also known as extracellular polymeric substances (EPS), which are responsible for forming complex three-dimensional structures involved in the adhesion and cohesion of the biofilms [14]. The EPS matrix has been considered as one of the main obstacles that limits the diffusion of antimicrobial agents, including phages, to the bacterial cells embedded in the biofilm [14].

Biofilm matrix is a reservoir of microbial enzymes secreted or released upon cell lysis (such as amidases and peptidases) that can lead to phage inactivation $[14,15]$. Biofilms are also composed by dead cells that can anchor phages and, in case of adsorbing to dead cells receptors, phages will not be able to infect living cells. Phages may also interact with some components of the matrix, namely with proteins, lipopolysaccharides, polysaccharides and teichoic acids [16,17], which ultimately may limit phage access to biofilm cells.

Phage diffusion through the biofilm matrix can be influenced by both phage morphology and biofilm density. Generally, the diffusion of phages through denser biofilms will be more difficult than through less dense biofilms [18]. Phage diffusion is also dependent on the biofilm architecture, and it is known that biofilms can exhibit different 3D shapes (mushroom-like, pillar-like, hilly, or flat multicellular structures) [19] that can be bathed by water channels making these biofilms, in theory, more prone to phage attack than dense biofilm structures. A recent study using LNA-FISH probes to image phage-biofilm interaction showed that phage infected cells were primarily located on the edges of water channels $\left[20^{\circ}\right]$.

\section{Reduced metabolic activity of biofilm bacterial cells}

The physiological state of cells has a great influence on phage replication since exponential-phase cells are more rapidly lysed than stationary-phase bacteria [21]. When a bacterial culture is under nutrient limitation, there is a transition between exponential to slow or no growth, which is commonly also observed in mature biofilms [22]. In biofilms, cells inhabiting the deeper layers and under oxygen and nutrient depletion conditions [5], have reduced metabolic activity constituting one of the main reasons why phages replicate faster in planktonic than biofilm cells. This physiological change is linked to the increased resistance or tolerance of biofilms to antibiotics, since the majority of antibiotics have no activity or impaired activity against non-dividing cells [22].

Although phages have activity against some bacterial host cells growing under nutrient limitation, their growth parameters are strongly influenced by the physiological state of the host cells $\left[23,24^{\bullet \bullet}\right]$. For instance, nutrient limitations of Escherichia coli cells resulted in severe inhibition of lytic development of phages $\lambda$, P1 and T4 [23]. More recently, Bryan et al. showed that the infection of stationary $E$. coli cells by the T4 phage at low MOIs did not progress until nutrient addition. These authors hypothesised that $\mathrm{T} 4$ responds to the starvation state of $E$. coli by entering what, the authors call a 'hibernation' mode, in which T4 initiates protein synthesis but arrests further phage development $\left[24^{\bullet \bullet}\right]$. The impaired activity of phages against stationary-phase cells has also been reported for phages infecting other bacterial species, such as Pseudomonas fluorescens [25], Klebsiella pneumoniae [26] and Staphylococcus epidermidis [27]. The amount of cells with reduced metabolic activity within biofilms are expected to increase throughout biofilm maturation, consequently older biofilms will be more difficult to tackle that young biofilms.

In literature there is a misconception about dormancy, persistence and stationary cells. It is often referred that part of the biofilm population is composed by dormant cells, which are cells that persist without division for extended periods [28]. This type of population is also part of suspended cultures and the number of dormant cells increases with the age of population, being very high in stationary growth cultures. Bacterial cells that persist after antibiotic treatment without undergoing genetic changes and revert to sensitive when cultured, are called persisters [29]. To the authors knowledge, there are no phage studies against persisters or dormant cells, therefore it would be important to fulfil this gap in order to better understand the interaction between phages and biofilms.

\section{Development of phage resistant sub-population within the biofilm}

Phage resistance mechanisms are crucial for bacterial survival in a set of different ecological niches. The four main resistance mechanisms described so far are: (i) prevention of phage DNA integration by superinfection exclusion systems; (ii) degradation of phage DNA by restriction-modification systems or by CRISPR-Cas systems; (iii) use of abortive infection systems that block phage replication, transcription or translation; and (iv) prevention of phage adsorption by loss or structural modifications of bacterial receptors, and/or masking phage receptor molecules by physical barriers such as 
the EPS matrix [30]. These mechanisms enable a quick adaptation of bacteria to the presence of phages and consequently, the emergence of phage-resistant mutants is almost inevitable.

Several studies have reported that the initial reduction of biofilm cells caused by phage treatment is usually followed by a fast proliferation of phage-resistant sub-populations within a short period of time [10,31-34]. For instance, the arising of phage-resistant bacterial variants resulting from $P$. aeruginosa biofilm treatment with phages was already reported [10,31]. Fu et al. studied the effect of lytic phages in the prevention of $P$. aeruginosa biofilm formation in hydrogel-coated catheters [10]. Although a reduction in biofilm formation was observed in the first $24 \mathrm{~h}$ comparatively to untreated catheters, a regrow of biofilms was observed between 24 and $48 \mathrm{~h}$, and phageresistant biofilm isolates were recovered [10]. Phageresistant bacteria was also observed in Serratia marcescens biofilms after $24 \mathrm{~h}$ of contact with phage [35]. In a study developed by Oechslin et al., the genomic profile of two $P$. aeruginosa phage-resistant strains was analysed and revealed mutations in genes encoding phage receptors, namely pilT and galU, when compared to the wild-type strain [36]. The same was reported by Pires $e t a l$. in which the authors described that mutations affecting the galU gene and the pil genes were responsible for bacterial resistance to phages $\left[13^{\circ}\right]$. This fact can be a consequence of the endogenous oxidative stress suffered by biofilm cells that leads to DNA damage within biofilms resulting in the development of genetic variants with high adaptability to external conditions $[37,38]$.

\section{Quorum sensing inhibits phage infection of biofilms}

Quorum sensing (QS) is a chemical communication process that bacteria use to regulate collective behaviours. Accordingly, QS molecules secreted by individual bacteria accumulates in dense bacterial populations enabling bacterial cells to recognise the population density and activate the corresponding response. QS is particularly important to regulate biofilm physiology and therefore believed to have a great impact in a biofilm population regulating virulence, growth and dispersion [39]. QS can be involved in the anti-phage process by reducing the phage receptor numbers on the cell surface as described for E. coli and Vibrio anguillarum [40,41]. In the case of $E$. coli, the number of receptors displayed at the bacterial surface for $\lambda$ phage docking is reduced in response to $\mathrm{N}$ acyl-1-homoserine lactone (AHL) quorum-sensing signals, causing a 2-fold reduction in the phage adsorption rate [40]. For $V$. anguillarum a similar mechanism was described. In this case, in high cell culture densities, a QS mediated down regulation of $o m p K$, the KVP40 receptor, was observed and rendered individual cells almost unsusceptible to phage infection [41]. Qin $e t$ al. observed an increased infection efficiency of the $P$. aeruginosa phage $\mathrm{K} 5$ in the presence of penicillic acid, a QS inhibitor [42].
In this work the authors did not find any alterations in phage adsorption rateand expression of cell receptors. According to the authors, this enhanced activity was probably due to an improved metabolic state of the cells [42]. QS mediated defensive mechanism can be a consequence of the biofilm phenotype itself, in which part of the cells exhibits a low metabolic state as a means to ensure efficient energy and resources to the biofilm population, which is controlled by QS mechanisms. Nevertheless, QS mediated mechanisms of defence to phages need to be further elucidated and described also for other species.

\section{Strategies to enhance biofilm control by phages}

In order to circumvent phage limitations and improve their performance for an efficient biofilm control, different approaches, such as synergistic combinations with other phages or antimicrobials, mechanical debridement of biofilms, and genetic engineering of phage genomes have been addressed (summarized in Figure 1). Some of the most relevant studies performed in vitro are indicated in Table 1.

\section{Mechanical debridement}

The hypothesis that a mechanical disruption of biofilms can facilitate phage infection has been studied in in vivo wound models. Seth et al., found that the tested phage was not active against Staphylococcus aureus intact biofilms [55]; however, when the phage was administered after sharp debridement, wound healing parameters assessed by histological analysis improved significantly and bacterial counts diminished [55]. In another study, using two different diabetes mellitus animal models (rodent and porcine), the combination of phages and debridement decreased bacterial counts of $P$. aeruginos a and $S$. aureus, and improved wound healing, particularly in the rodent model [56].

Overall, it can be assumed that debridement enhances phage infection as a consequence of a better phage accessibility to the biofilm cells. Moreover, cells released due to debridement also become more susceptible to phage infection [8], suggesting that this type of approach can be valuable therapeutically.

\section{Combined therapy with antibiotics and antiseptics}

The combination of phages with other antimicrobial agents, such as antibiotics or antiseptics, has been widely studied. Previous studies have suggested that sublethal concentrations of antibiotics can improve the production and activity of virulent phages, a phenomenon called phage-antibiotic synergy (PAS) [43,57]. The synergistic effect of phages and antibiotics has been studied in planktonic cultures (reviewed in $\left[58^{\circ}\right]$ ) and expanded to biofilms $[43,46]$. For instance, Ryan et al. evaluated the effect of a combined treatment of T4 phage and cefotaxime in the eradication of E. coli ATCC 11303 biofilms. The combination of phage and antibiotic 


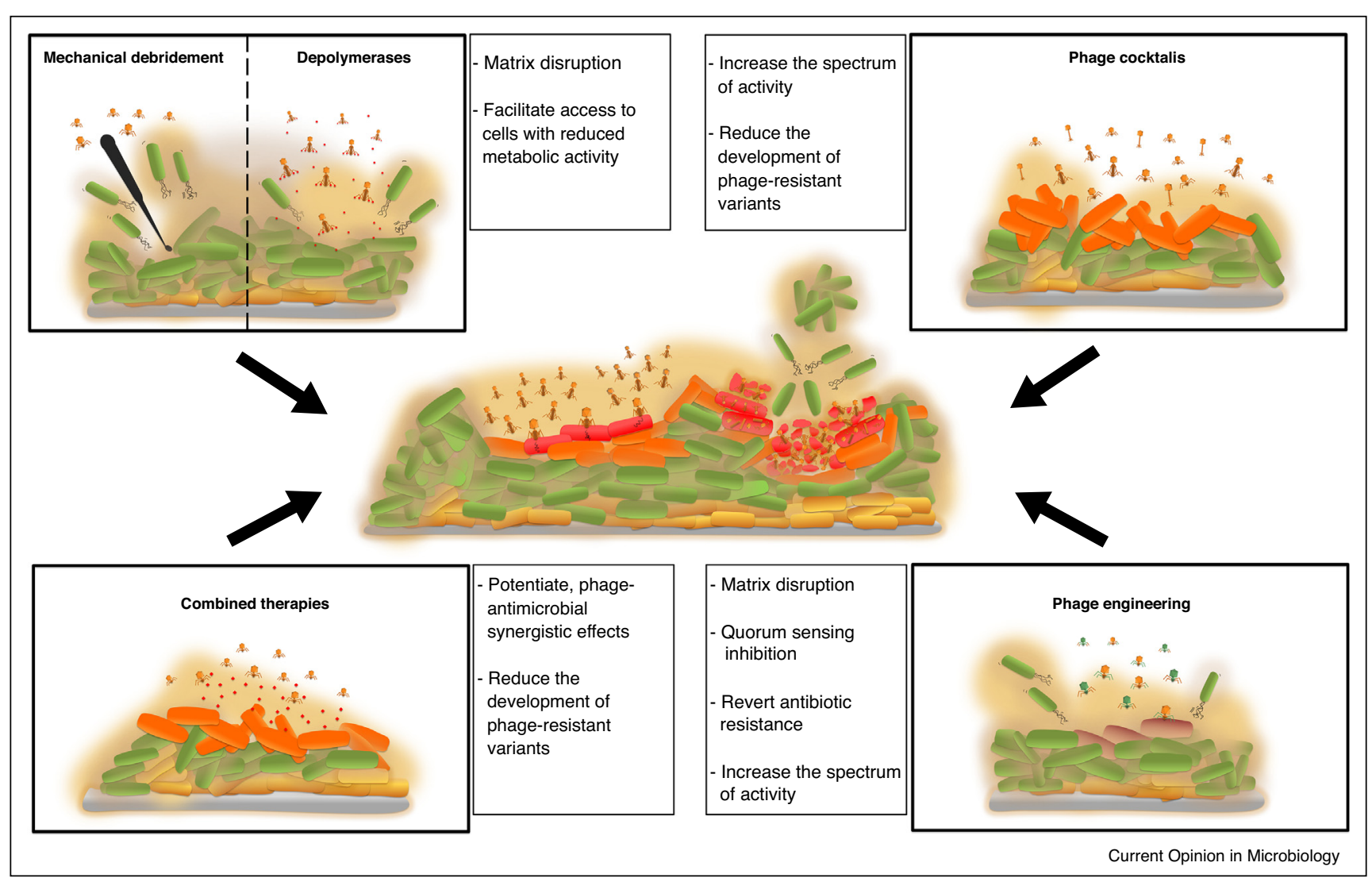

Schematic representation of strategies to overcome biofilm barriers using phages and combined therapies. The biofilm is represented by cells under different metabolic conditions and susceptibility to phages (red cells: phage infected cells; green cells: metabolically active cells; orange cells: phage-resistant variants; yellow cells: low metabolic activity).

significantly enhanced the biofilm eradication compared with antibiotic alone; for example, the use of phages (titres of $10^{4}$ and $10^{7} \mathrm{PFU} \mathrm{mL} \mathrm{mL}^{-1}$ ) reduced the minimum biofilm eradication concentration (MBEG) of cefotaxime against $E$. coli biofilms by 2 and 8 folds, respectively [43]. Combinations of phages and antibiotics were also tested against $S$. aureus [46] and K. pneumoniae [44] biofilms resulting in an improved efficacy of biofilm control compared to what was obtained after the use of each antimicrobial alone.

Nonetheless, the combination of phages with antibiotics has not always resulted in improved biofilm removal efficacy. For example, the lytic K. pneumoniae KPO1K2 phage was used alone or combined with ciprofloxacin to treat $K$. pneumoniae biofilms and no significant differences in biofilm removal efficacies between both treatments were observed [45]. However, the combined therapy significantly restricted the formation of resistant variants compared with each treatment alone [45]. It has been described that the order of treatment might have a great impact on the outcome of biofilm control. Chaudhry et al. concluded that in most cases the use of phages before antibiotics resulted in maximum killing of $P$. aeruginosa biofilms in vitro. The combined treatment was particularly effective against biofilms grown on layers of cultured epithelial cells $\left[59^{\circ}\right]$.

Besides antibiotics, the synergistic effect between phages and antiseptics has also been studied. Using a continuous flow system or microtiter plates, a combined therapy of chlorine and phages revealed to be more effective in controlling $P$. aeruginosa biofilm growth and removing pre-formed biofilms than the separate use of each therapy [48].

\section{Combined therapy with enzymes}

It was believed that depolymerases, which are polysaccharide-degrading enzymes encoded in phage genomes, could be potentially used by phages to circumvent the biofilm barrier and facilitate the phage access to the host cells $[60,61]$. However, the main function of depolymerases consists in the degradation of capsular polysaccharides to facilitate phage adsorption $\left[62-64,65^{\circ}\right]$ rather 
Some of the most relevant studies about the in vitro efficacy of phages against biofilms

\begin{tabular}{lll} 
& Phage(s) & \multicolumn{1}{c}{ Experimental approach } \\
\hline $\begin{array}{lll}\text { Combined therapy } \\
\text { E. coli }\end{array}$ & & $\begin{array}{l}\text { The antimicrobial synergy between T4 phage and } \\
\text { cefotaxime in the eradication of } E \text {. coli biofilms was }\end{array}$ \\
& & evalia
\end{tabular}

\section{K. pneumoniae Uncharacterized}

K. pneumoniae KPO1K2

S. aureus

SAP-26

E. coli and

P. aeruginosa

T4 and PB-

P. aeruginosa

P. aeruginosa Cocktail of RNA phages

\section{Phage cocktails}

P. mirabilis

P. mirabilis

$P$. aeruginosa

\section{$P$. aeruginosa}

and $P$. mirabilis

S. aureus $P$. mirabilis phages cefotaxime

evaluated
$K$. pneumoniae biofilms of different ages were subjected to phage treatment (MOI of 0.01$)$ in combination with amoxicillin $(512 \mu \mathrm{g} / \mathrm{mL})$

$12 \mathrm{~h}$ old $K$. pneumoniae biofilms were subjected to the combined treatment of phage (MOI of 1 ) and ciprofloxacin (1 mg/L)

Phage $\left(10^{8} \mathrm{PFU}\right)$ was applied together with azithromycin $(80 \mathrm{mg} / \mathrm{L})$, vancomycin $(10 \mathrm{mg} / \mathrm{L})$, and rifampicin $(0.6 \mathrm{mg} / \mathrm{L})$ against $24 \mathrm{~h}$ old $\mathrm{S}$. aureus biofilms

E. coli and $P$. aeruginosa $48 \mathrm{~h}$ biofilms were exposed to a combination of tobramycin $(2 \mu \mathrm{g} / \mathrm{mL})$ and T4 phage (MOI of $0.01)$ or tobramycin $(0.5 \mu \mathrm{g} / \mathrm{mL}$ ) and PB-1 phage (MOI of 0.01 ) for $24 \mathrm{~h}$, respectively

A mixture of phages and chlorine with different concentrations was tested to control and remove $P$. aeruginosa biofilms

Catheters were pre-treated with the phage cocktail before bacterial inoculation

Models mimicking either an established infection, or early colonization the catheters, were treated with a single dose of phage cocktal

Catheters were pre-treated with a cocktail of five phages prior to bacterial inoculation

Cocktail of six $P$. aeruginosa phages and cocktail of four

Mixture of phage $\mathrm{K}$ and six of its derivatives
Hydrogel-coated catheters were pre-treated with one or both phage cocktails before bacterial challenge

The phage cocktail was used to prevent biofilm formation and to remove established biofilms
Results

Reference

The use of phages (titres of $10^{4}$ and $10^{7} \mathrm{PFU} \mathrm{mL}{ }^{-1}$ ) reduced the MBEC of cefotaxime against $E$. coli biofilms by 2 and 8 folds, respectively

A significant reduction of the biofilm bacterial counts was observed after combined therapy application

No significant differences in biofilm removal efficacies between phage treatment alone or combined with ciprofloxacin were observed. However, the combined treatment significantly prevented the emergence of resistant variants

Phage alone was able to kill approximately $28 \%$ of the biofilm bacteria after $24 \mathrm{~h}$. Azithromycin and vancomycin could kill $25 \%$ and $17 \%$, respectively and when biofilms were treated with phage and rifampicin $\sim 35 \%$ of the live cells remained after this treatment. Phage/azithromycin and phage/vancomycin treatments showed $\sim 40 \%$ and $60 \%$ cells alive after $24 \mathrm{~h}$, respectively

The combination of phage and antibiotic led to 99.99\% decrease on the survival of $E$. coli biofilms compared to the use of tobramycin alone, while the combination of tobramycin and PB-1 on $P$. aeruginosa biofilms was just as effective as tobramycin alone in decreasing biofilm cells. However, phage infection in combination with tobramycin reduced the emergence of antibiotic and phage resistant cells

The phage cocktail $\left(3 \times 10^{7} \mathrm{PFU} \mathrm{mL} \mathrm{m}^{-1}\right)$ and chlorine $(210 \mathrm{mg} / \mathrm{L})$ reduced biofilm growth by $\sim 94 \%$ and removed $\sim 88 \%$ of existing biofilms

A significant reduction in the number of $P$. mirabilis biofilm cells was observed after 96 and $168 \mathrm{~h}$ of biofilm formation in phagecoated catheters

In models simulating established infection, a single dose of phage cocktail significantly extended the time taken for catheters to block ( 3 fold), compared to untreated control In models simulating an early stage infection, the phage cocktail completely prevented catheter blockage and eradicated infection

The pretreatment of catheters with the phage cocktail resulted in a 3 -log reduction of biofilm cell populations after $48 \mathrm{~h}$, compared with untreated catheters

Phage pretreatment reduced $P$. aeruginosa biofilm counts by $4 \log _{10} \mathrm{CFU} / \mathrm{cm}^{2}$ and $P$. mirabilis biofilm counts by $>2 \log _{10} \mathrm{CFU} /$ $\mathrm{cm}^{2}$ over $48 \mathrm{~h}$

Crystal violet staining assays revealed that the main reduction of biofilm biomass occurred between 15 and $20 \mathrm{~h}$ after phage treatment. Furthermore, a complete inhibition of $S$. aureus biofilm formation over a period of $48 \mathrm{~h}$ was observed 


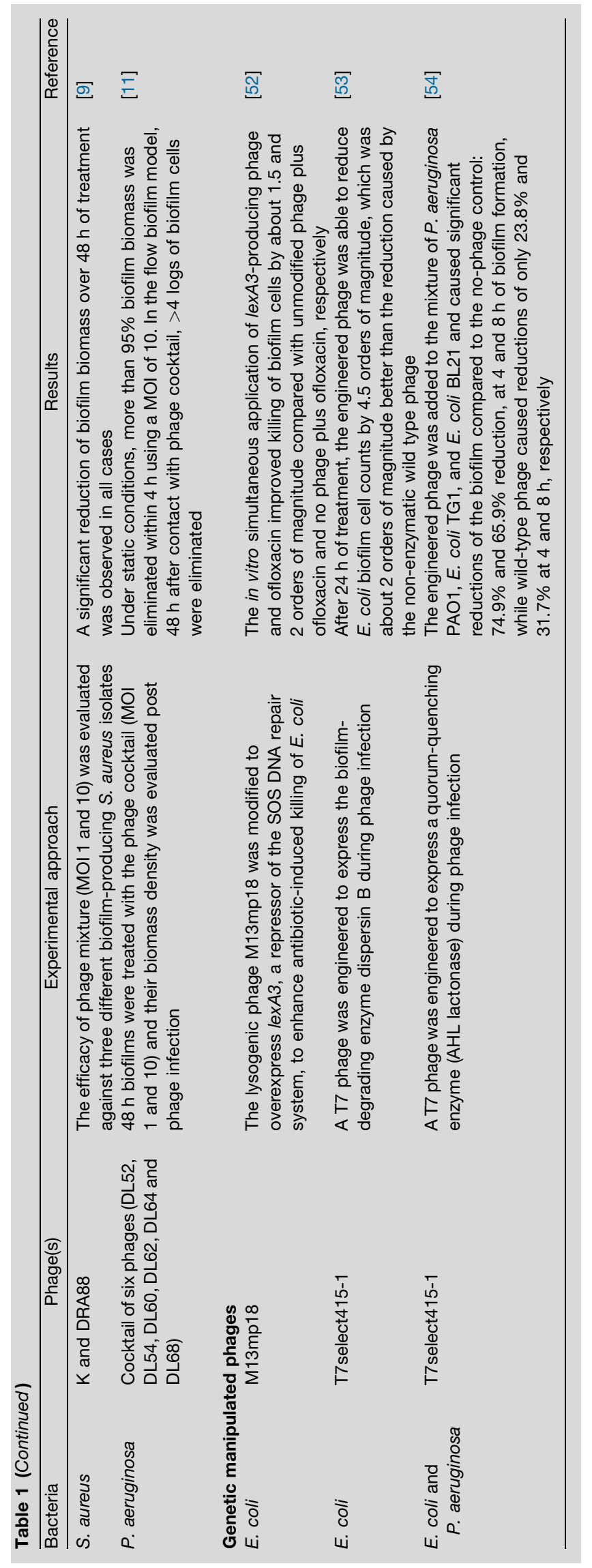

than cleavage of EPS present in biofilm matrix. These enzymes encoded by phages can be heterologously expressed, purified and added to planktonic bacteria and biofilms, to degrade the capsular polysaccharides and enhance phage killing [66-68]. Studies performed by Cornelissen et al. showed that although Pseudomonas putida phages encoding polysaccharide depolymerases revealed biofilm degradation properties, the application of the recombinantly expressed phage depolymerases or non-infectious phage particles (UV inactivated) to biofilms did not exhibit biofilm-degrading properties $[66,67]$. These studies showed that depolymerases alone were not capable of degrading $P$. putida biofilms and highlighted the role of phage amplification in biofilm degradation $[66,67]$. Nonetheless, in a study developed by Gutiérrez et al., a depolymerase derived from a S. epidermidis phage was expressed and applied to biofilms and, although dosedependent, it revealed biofilm removal properties, which were evaluated by viable cell counting and crystal violet staining of total biofilm biomass [69].

\section{Phage cocktails}

Multiple phages with different host ranges and targeting different receptors can be combined in a single phage preparation (phage cocktails) to expand their spectrum of activity and prevent the development of phage-resistant bacterial variants [70]. Several studies have reported the use of this strategy to treat bacterial biofilms $[2,10,11,51,71]$. For example, Fu et al. studied the prevention of $P$. aeruginosa biofilm formation on hydrogelcoated catheters pre-treated with phages [10]. In that work, a cocktail of 5 phages was developed after evaluating their efficacy against phage-resistant biofilm variants recovered from single phage treated catheters. The pretreatment of catheters with phage cocktail resulted in a reduction of 3 orders-of-magnitude in the number of biofilm cells after $48 \mathrm{~h}$, compared with untreated catheters [10]. According to the authors, the use of phage cocktails could be potentially applied in indwelling medical devices to prevent bacterial colonization and biofilm formation, which might inhibit the development of bacterial infections. Similarly, a recent study evaluated the potential of phage cocktails (a cocktail of six P. aeruginosa phages and a cocktail of four Proteus mirabilis phages) to prevent single and mixed species $P$. aeruginosa and $P$. mirabilis biofilm formation [2]. Hydrogel-coated catheters were pre-treated with one or both phage cocktails and significant reductions in biofilm cell counts were observed in both cases [2].

Phage cocktails have also been successfully used to target $S$. aureus biofilms. In a biofilm prevention study, crystal violet staining assays revealed a complete inhibition of $S$. aureus biofilm formation over a period of $48 \mathrm{~h} \mathrm{[51].} \mathrm{Other}$ studies have used phage cocktails to treat pre-formed $S$. aureus biofilms and significant biofilm biomass reductions were also observed [9,72]. 


\section{Genetic manipulation of phages}

Recent advances in biotechnology and synthetic biology fields have enabled the development of a new generation of phages designed for specific purposes. For instance, $\mathrm{Lu}$ and Collins genetically engineered the $\mathrm{T} 7$ phage to express a biofilm-degrading enzyme dispersin B during phage infection [53]. Thus, the engineered phage was able to simultaneously kill the biofilm cells and degrade the biofilm matrix resulting in an improved efficacy of biofilm removal than the wild type phage [53]. After $24 \mathrm{~h}$ of treatment, the engineered phage was able to reduce $E$. coli TG1 biofilms by 4.5 orders-of-magnitude, which was about 2 orders-of-magnitude better than the reduction caused by the non-enzymatic wild type phage [53].

To understand the stability of such mutation in engineered phages, Schmerer et al. studied whether the transgene will be lost or maintained during phage replication [73]. Although the engineered enzymatic phage was better than wild type phage in clearing short-term biofilms, no significant differences were observed in clearing long-term biofilms ( 7 days), indicating that dispersin B has no effect in old biofilms. However, it was further observed that the frequency of the dispersin transgene increased in both short-term and long-term biofilms at least temporarily [73].

In another study reported by Lu and Collins, a filamentous phage was engineered to enhance the efficacy of antibiotic therapy [52]. The engineered phage overexpressed a repressor of the SOS DNA repair system in $E$. coli and its application resulted in an improved activity of antibiotics against antibiotic-resistant bacteria, persister cells and biofilm cells [52].

Pei et al. engineered T7 phage to encode a quorumquenching enzyme (acyl homoserine lactonase (AHL)) that has broad-range specificity for cleaving the lactone rings of diverse AHLs. The engineered phage was able to degrade the AHLs from many bacteria and to inhibit the formation of mixed-species biofilms composed by $P$. aeruginosa and E. coli [54].

\section{Conclusions}

Phage therapy is an attractive option to prevent and control biofilm related infections. Apparently, due to the close proximity of cells, phage infection of biofilms seems to be very efficient. However, in a closer look, the biofilm phenotype also offers protection to cells against phage attack. The dense biofilm matrix, the low metabolic state of biofilm cells and the rapid proliferation of phage resistant variants are some of the features that hitch biofilm/phage interactions. Consequently, it is difficult to efficiently control a biofilm population with only one phage. Therefore we propose combined therapies to overcome biofilm barriers to phage infection and genetically engineered phages with new functions to turn them more effective biofilm controllers. Further progress is also required to understanding of how bacterial cells respond to different therapeutic approaches, preferentially at a single-cell level. We consider also important to normalize biofilm studies, using biofilm formation set-up that best mimic real biofilm environments.

\section{Conflict of interest}

None.

\section{Acknowledgements}

This work was supported by the Portuguese Foundation for Science and Technology (FCT) under the scope of the project PTDC/BBB-BSS/6471/ 2014 , the strategic funding of UID/BIO/04469/2013 unit and COMPETE 2020 (POCI-01-0145-FEDER-006684). This work was also supported by BioTecNorte operation (NORTE-01-0145-FEDER-000004) funded by the European Regional Development Fund under the scope of Norte2020 Programa Operacional Regional do Norte.

\section{References and recommended reading}

Papers of particular interest, published within the period of review, have been highlighted as:

- of special interest

$\bullet$ of outstanding interest

1. Flemming H-C, Wingender J, Szewzyk U, Steinberg P, Rice SA, Kjelleberg S: Biofilms: an emergent form of bacterial life. Nat Rev Microbiol 2016, 14:563-575.

2. Lehman SM, Donlan RM: Bacteriophage-mediated control of a two-species biofilm formed by microorganisms causing catheter-associated urinary tract infections in an in vitro urinary catheter model. Antimicrob Agents Chemother 2015, 59:1127-1137.

3. Gutiérrez D, Vandenheuvel D, Martínez B, Rodríguez A, Lavigne R, García P: Two phages, philPLA-RODI and phiIPLA-C1C, lyse mono- and dual-species Staphylococcal biofilms. Appl Environ Microbiol 2015, 81:3336-3348.

4. Azeredo J, Sutherland IW: The use of phages for the removal of infectious biofilms. Curr Pharm Biotechnol 2008, 9:261-266.

5. Sillankorva S, Azeredo J: The use of bacteriophages and bacteriophage-derived enzymes for clinically relevant biofilm control. In Phage Therapy: Current Research and Applications. Edited by Borysowski J, Mie?dzybrodzki R, Górski A. 2014.

6. Abedon ST: Thinking about microcolonies as phage targets. Bacteriophage 2012, 2:200-204.

7. Donlan RM: Preventing biofilms of clinically relevant organisms using bacteriophage. Trends Microbiol 2009, 17:6672 .

8. Harper D, Parracho H, Walker J, Sharp R, Hughes G, Werthén M, Lehman S, Morales S: Bacteriophages and Biofilms. Antibiotics 2014, 3:270-284.

9. Alves DR, Gaudion A, Bean JE, Perez Esteban P, Arnot TC, Harper DR, Kot W, Hansen LH, Enright MC, Jenkins ATA: Combined use of bacteriophage $\mathrm{K}$ and a novel bacteriophage to reduce Staphylococcus aureus biofilm formation. Appl Environ Microbiol 2014, 80:6694-6703.

10. Fu W, Forster T, Mayer O, Curtin JJ, Lehman SM, Donlan RM: Bacteriophage cocktail for the prevention of biofilm formation by Pseudomonas aeruginosa on catheters in an in vitro model system. Antimicrob Agents Chemother 2010, 54:397-404.

11. Alves DR, Perez-Esteban $P$, Kot W, Bean JE, Arnot T, Hansen LH, Enright MC, Jenkins ATA: A novel bacteriophage cocktail reduces and disperses Pseudomonas aeruginosa biofilms under static and flow conditions. Microb Biotechnol 2015, 9:61-74. 
12. Alemayehu D, Casey PG, McAuliffe O, Guinane CM, Martin JG, Shanahan F, Coffey A, Ross RP, Hill C: Bacteriophages $\varphi$ MR2992 and $\varphi \mathrm{NH}-4$ can eliminate Pseudomonas aeruginosa in the murine lung and on cystic fibrosis lung airway cells. MBio 2012 3 e00029-12.

13. Pires DP, Dötsch A, Anderson EM, Hao Y, Khursigara CM, Lam JS,

- $\quad$ Sillankorva S, Azeredo J: A genotypic analysis of five $\boldsymbol{P}$. aeruginosa strains after biofilm infection by phages targeting different cell surface receptors. Front Microbiol 2017, 8:1229.

In this study the authors followed the progression of bacteriophage insensitive mutants in a biofilm infected by phages targeting diferent cell receptors.

14. Flemming $\mathrm{H}-\mathrm{C}$, Wingender J: The biofilm matrix. Nat Rev Microbiol 2010, 8:623-633.

15. Romaní AM, Fund K, Artigas J, Schwartz T, Sabater S, Obst U: Relevance of polymeric matrix enzymes during biofilm formation. Microb Ecol 2008, 56:427-436

16. Drulis-Kawa Z, Majkowska-Skrobek G, Maciejewska B: Bacteriophages and phage-derived proteins - application approaches. Curr Med Chem 2015, 22:1757-1773.

17. Rakhuba DV, Kolomiets El, Szwajcer Dey E, Novik GI: Bacteriophage receptors, mechanisms of phage adsorption and penetration into host cell. Pol J Microbiol 2010 59:145-155.

18. Hu J, Miyanaga K, Tanji Y: Diffusion properties of bacteriophages through agarose gel membrane. Biotechnol Prog 2010, 26:1213-1221.

19. Pamp SJ, Sternberg C, Tolker-Nielsen T: Insight into the microbial multicellular lifestyle via flow-cell technology and confocal microscopy. Cytometry Part A 2009, 75A:90-103.

20. Vilas Boas D, Almeida C, Sillankorva S, Nicolau A, Azeredo J,

- $\quad$ Azevedo NF: Discrimination of bacteriophage infected cells using locked nucleic acid fluorescent in situ hybridization (LNA-FISH). Biofouling 2016, 32:179-190.

This work studied the progression of phage infected cells within the biofilm using LNA probes.

21. Storms ZJ, Brown T, Cooper DG, Sauvageau D, Leask RL: Impact of the cell life-cycle on bacteriophage T4 infection. FEMS Microbiol Lett 2014, 353:63-68.

22. Mah TF, O'Toole GA: Mechanisms of biofilm resistance to antimicrobial agents. Trends Microbiol 2001, 9:34-39.

23. Łoś M, Golec P, Łoś JM, Weglewska-Jurkiewicz A, Czyz A, Wegrzyn A, Wegrzyn G, Neubauer P: Effective inhibition of lytic development of bacteriophages lambda, P1 and T4 by starvation of their host, Escherichia coli. BMC Biotechnol 2007 7:13.

24. Bryan D, El-Shibiny A, Hobbs Z, Porter J, Kutter EM:

- Bacteriophage T4 infection of stationary phase E. coli: life after log from a phage perspective. Front Microbiol 2016, 7:1391.

This paper thoroughly describes the patterns of T4 phage infection of stationary-phase cells. The authors identified a new 'hibernation' mode of long-term interaction.

25. Sillankorva S, Oliveira R, Vieira MJ, Sutherland I, Azeredo J: Pseudomonas fluorescens infection by bacteriophage $\Phi$ s1: The influence of temperature, host growth phase and media. FEMS Microbiol Lett 2004, 241:13-20.

26. Jamal M, Hussain T, Das CR, Andleeb S: Characterization of Siphoviridae phage $\mathbf{Z}$ and studying its efficacy against multidrug-resistant Klebsiella pneumoniae planktonic cells and biofilm. J Med Microbiol 2015, 64:454-462.

27. Cerca N, Oliveira R, Azeredo J: Susceptibility of Staphylococcus epidermidis planktonic cells and biofilms to the lytic action of Staphylococcus bacteriophage K. Lett Appl Microbiol 2007, 45:313-317.

28. Wood TK, Knabel SJ, Kwan BW: Bacterial persister cell formation and dormancy. Appl Environ Microbiol 2013 79:7116-7121.
29. Shapiro JA, Nguyen VL, Chamberlain NR: Evidence for persisters in Staphylococcus epidermidis RP62a planktonic cultures and biofilms. J Med Microbiol 2011, 60:950-960.

30. Labrie SJ, Samson JE, Moineau S: Bacteriophage resistance mechanisms. Nat Rev Microbiol 2010, 8:317-327.

31. Pires D, Sillankorva S, Faustino A, Azeredo J: Use of newly isolated phages for control of Pseudomonas aeruginosa PAO and ATCC 10145 biofilms. Res Microbiol 2011, 162:798-806.

32. Hosseinidoust Z, Tufenkji N, van de Ven TGM: Predation in homogeneous and heterogeneous phage environments affects virulence determinants of Pseudomonas aeruginosa. Appl Environ Microbiol 2013, 79:2862-2871.

33. Le S, Yao X, Lu S, Tan Y, Rao X, Li M, Jin X, Wang J, Zhao Y, Wu NC et al.: Chromosomal DNA deletion confers phage resistance to Pseudomonas aeruginosa. Sci Rep 2014, 4:4738.

34. Lacqua A, Wanner O, Colangelo T, Martinotti MG, Landini P: Emergence of biofilm-forming subpopulations upon exposure of Escherichia coli to environmental bacteriophages. Appl Environ Microbiol 2006, 72:956-959.

35. Zhang J, Örmälä-Odegrip A-M, Mappes J, Laakso J: Top-down effects of a lytic bacteriophage and protozoa on bacteria in aqueous and biofilm phases. Ecol Evol 2014, 4:4444-4453.

36. Oechslin F, Piccardi P, Mancini S, Gabard J, Moreillon P, Entenza JM, Resch G, Que Y-A: Synergistic interaction between phage therapy and antibiotics clears Pseudomonas aeruginosa infection in endocarditis and reduces virulence. $J$ Infect Dis 2016 http://dx.doi.org/10.1093/infdis/jiw632.

37. Moyano AJ, Tobares RA, Rizzi YS, Krapp AR, Mondotte JA, Bocco JL, Saleh M-C, Carrillo N, Smania AM: A long-chain flavodoxin protects Pseudomonas aeruginosa from oxidative stress and host bacterial clearance. PLoS Genet 2014, 10: e1004163.

38. Poole K: Bacterial stress responses as determinants of antimicrobial resistance. J Antimicrob Chemother 2012, 67:2069-2089.

39. Papenfort K, Bassler BL: Quorum sensing signal-response systems in Gram-negative bacteria. Nat Rev Microbiol 2016, 14:576-588.

40. Høyland-Kroghsbo NM, Maerkedahl RB, Svenningsen SL: A quorum-sensing-induced bacteriophage defense mechanism. MBio 2013, 4:e00362-e412.

41. Tan D, Svenningsen SL, Middelboe M: Quorum sensing determines the choice of antiphage defense strategy in Vibrio anguillarum. MBio 2015, 6:e00627.

42. Qin X, Sun Q, Yang B, Pan X, He Y, Yang H: Quorum sensing influences phage infection efficiency via affecting cell population and physiological state. J Basic Microbiol 2017, 57:162-170.

43. Ryan EM, Alkawareek MY, Donnelly RF, Gilmore BF: Synergistic phage-antibiotic combinations for the control of Escherichia coli biofilms in vitro. FEMS Immunol Med Microbiol 2012, 65:395398.

44. Bedi MS, Verma V, Chhibber S: Amoxicillin and specific bacteriophage can be used together for eradication of biofilm of Klebsiella pneumoniae B5055. World J Microbiol Biotechnol 2009, 25:1145-1151.

45. Verma V, Harjai K, Chhibber S: Restricting ciprofloxacininduced resistant variant formation in biofilm of Klebsiella pneumoniae B5055 by complementary bacteriophage treatment. J Antimicrob Chemother 2009, 64:1212-1218.

46. Rahman M, Kim S, Kim SM, Seol SY, Kim J: Characterization of induced Staphylococcus aureus bacteriophage SAP-26 and its anti-biofilm activity with rifampicin. Biofouling 2011 , 27:1087-1093.

47. Coulter LB, McLean RJC, Rohde RE, Aron GM: Effect of bacteriophage infection in combination with tobramycin on the emergence of resistance in Escherichia coli and Pseudomonas aeruginosa biofilms. Viruses 2014, 6:3778-3786. 
48. Zhang Y, Hu Z: Combined treatment of Pseudomonas aeruginosa biofilms with bacteriophages and chlorine. Biotechnol Bioeng 2013, 110:286-295.

49. Melo LDR, Veiga P, Cerca N, Kropinski AM, Almeida C, Azeredo J, Sillankorva S: Development of a phage cocktail to control Proteus mirabilis catheter-associated urinary tract infections. Front Microbiol 2016, 7:1024.

50. Nzakizwanayo J, Hanin A, Alves DR, McCutcheon B, Dedi C, Salvage J, Knox K, Stewart B, Metcalfe A, Clark J et al.: Bacteriophage can prevent encrustation and blockage of urinary catheters by Proteus mirabilis. Antimicrob Agents Chemother 2015, 60:1530-1536.

51. Kelly D, McAuliffe O, Ross RP, Coffey A: Prevention of Staphylococcus aureus biofilm formation and reduction in established biofilm density using a combination of phage $\mathrm{K}$ and modified derivatives. Lett Appl Microbiol 2012, 54:286-291.

52. Lu TK, Collins JJ: Engineered bacteriophage targeting gene networks as adjuvants for antibiotic therapy. Proc Natl Acad Sci U S A 2009, 106:4629-4634.

53. Lu TK, Collins JJ: Dispersing biofilms with engineered enzymatic bacteriophage. Proc Natl Acad Sci U S A 2007, 104:11197-11202.

54. Pei R, Lamas-Samanamud GR: Inhibition of biofilm formation by T7 bacteriophages producing quorum-quenching enzymes. Appl Environ Microbiol 2014, 80:5340-5348.

55. Seth AK, Geringer MR, Nguyen KT, Agnew SP, Dumanian Z, Galiano RD, Leung KP, Mustoe TA, Hong SJ: Bacteriophage therapy for Staphylococcus aureus biofilm-infected wounds: a new approach to chronic wound care. Plast Reconstr Surg 2013, 131:225-234.

56. Mendes JJ, Leandro C, Corte-Real S, Barbosa R, Cavaco-Silva P Melo-Cristino J, Górski A, Garcia M: Wound healing potential of topical bacteriophage therapy on diabetic cutaneous wounds. Wound Repair Regen 2013, 21:595-603.

57. Kamal F, Dennis JJ: Burkholderia cepacia complex PhageAntibiotic Synergy (PAS): antibiotics stimulate lytic phage activity. Appl Environ Microbiol 2015, 81:1132-1138.

58. Torres-Barceló C, Hochberg ME: Evolutionary rationale for

- $\quad$ phages as complements of antibiotics. Trends Microbiol 2016, 24:249-256.

A comprehensive review about the combination of phages and antibiotics.

59. Chaudhry WN, Concepción-Acevedo J, Park T, Andleeb S, Bull JJ,

- Levin BR: Synergy and order effects of antibiotics and phages in killing pseudomonas aeruginosa biofilms. PLOS ONE 2017, 12:e0168615.

This paper studied the potential of combinations of phages and antibiotics for the treatment of $P$. aeruginosa biofilms, highlighting the order effects of the combined therapy.

60. Hughes KA, Sutherland IW, Jones MV: Biofilm susceptibility to bacteriophage attack: the role of phage-borne polysaccharide depolymerase. Microbiology 1998, 144:3039-3047.
61. Yan J, Mao J, Mao J, Xie J: Bacteriophage polysaccharide depolymerases and biomedical applications. BioDrugs 2014, 28:265-274.

62. Scholl D, Rogers S, Adhya S, Merril CR: Bacteriophage K1-5 encodes two different tail fiber proteins, allowing it to infect and replicate on both $\mathrm{K} 1$ and $\mathrm{K} 5$ strains of Escherichia coli. J Virol 2001, 75:2509-2515.

63. Glonti T, Chanishvili N, Taylor PW: Bacteriophage-derived enzyme that depolymerizes the alginic acid capsule associated with cystic fibrosis isolates of Pseudomonas aeruginosa. J Appl Microbiol 2010, 108:695-702.

64. Lin T-L, Hsieh P-F, Huang Y-T, Lee W-C, Tsai Y-T, Su P-A, Pan YJ, Hsu C-R, Wu M-C, Wang J-T: Isolation of a bacteriophage and its depolymerase specific for K1 capsule of Klebsiella pneumoniae: implication in typing and treatment. $J$ Infect Dis 2014, 210:1734-1744.

65. Pan $Y-J$, Lin T-L, Chen C-C, Tsai $Y-T$, Cheng $Y-H$, Chen $Y-Y$,

- Hsieh P-F, Lin Y-T, Wang J-T: Klebsiella phage ФK64-1 encodes multiple depolymerases for multiple host capsular types. $J$ Virol 2017, 91 http://dx.doi.org/10.1128/JVI.02457-16.

In this paper eight novel capsule depolymerases where identified in a multihost Klebisiella phage.

66. Cornelissen A, Ceyssens P-J, T'Syen J, Van Praet H, Noben J-P Shaburova OV, Krylov VN, Volckaert G, Lavigne R: The T7-related Pseudomonas putida phage $\varphi 15$ displays virion-associated biofilm degradation properties. PLOS ONE 2011, 6:e18597.

67. Cornelissen A, Ceyssens P-J, Krylov VN, Noben J-P, Volckaert G, Lavigne R: Identification of EPS-degrading activity within the tail spikes of the novel Pseudomonas putida phage AF. Virology 2012, 434:251-256.

68. Majkowska-Skrobek G, Ła?tka A, Berisio R, Maciejewska B, Squeglia F, Romano M, Lavigne R, Struve C, Drulis-Kawa Z: Capsule-targeting depolymerase, derived from Klebsiella KP36 phage, as a tool for the development of anti-virulent strategy. Viruses 2016, 8:324.

69. Gutiérrez D, Briers Y, Rodríguez-Rubio L, Martínez B, Rodríguez A, Lavigne R, García P: Role of the pre-neck appendage protein (Dpo7) from phage vB_SepiS-philPLA7 as an anti-biofilm agent in Staphylococcal species. Front Microbiol 2015, 6:1315.

70. Chan BK, Abedon ST, Loc-Carrillo C: Phage cocktails and the future of phage therapy. Future Microbiol 2013, 8:769-783.

71. Mendes JJ, Leandro C, Mottola C, Barbosa R, Silva FA, Oliveira M, Vilela CL, Melo-Cristino J, Gorski A, Pimentel M et al.: In vitro design of a novel lytic bacteriophage cocktail with therapeutic potential against organisms causing diabetic foot infections. $J$ Med Microbiol 2014, 63:1055-1065.

72. Drilling A, Morales S, Jardeleza C, Vreugde S, Speck P, Wormald P-J: Bacteriophage reduces biofilm of Staphylococcus aureus ex vivo isolates from chronic rhinosinusitis patients. Am J Rhinol Allergy 2014, 28:3-11.

73. Schmerer M, Molineux IJ, Ally D, Tyerman J, Cecchini N, Bull JJ: Challenges in predicting the evolutionary maintenance of a phage transgene. J Biol Eng 2014, 8:21. 